\title{
URBAN HERITAGE TOURISM Sebuah konsep pelestarian melalui pendekatan pariwisata
}

\author{
Mutiawati Mandaka ${ }^{1}$, Ikaputra ${ }^{2}$ \\ Program Studi Arsitektur Fakultas Teknik Universitas Pandanaran ${ }^{1}$ \\ Departemen Arsitektur dan Perencanaan Fakultas Teknik Universitas Gadjah Mada ${ }^{2}$ \\ mutia.mandaka@mail.ugm.ac.id'1 \\ ikaputra@ugm.ac.id²
}

\begin{abstract}
Historical buildings in various cities in Indonesia are important assets that need to be preserved and have the potential to be developed. The importance of maintaining this historic asset gave rise to a concept. The purpose of this study is to examine more deeply how urban heritage can be maintained, inherited, and passed on to future generations through tourism activities so that it can still become the identity and character of a city. The method used in this paper is the literature study method. The literature references used are all related to urban, heritage and tourism. Based on the literature study that has been made, it can be concluded that urban heritage tourism is a concept that combines tourism with the maintenance of historic buildings by understanding the principles of heritage, planning conservation for heritage, understanding the principles of planning and developing urban heritage tourism and applying urban heritage. tourism without reducing the prevailing cultural values so that urban heritage tourism has the opportunity to describe the past to be presented in the present and in the future as the attraction of a city.
\end{abstract}

Keywords: heritage, concept, tourism, urban

\begin{abstract}
Abstrak
Bangunan-bangunan bersejarah yang ada di berbagai kota di Indonesia merupakan aset penting yang perlu dilestarikan keberadaannya dan berpotensi untuk bisa dikembangkan. Pentingnya pemeliharaan aset bersejarah ini memunculkan sebuah konsep. Tujuan penelitian ini untuk mengkaji lebih mendalam bagaimana melestarikan bangunan-bangunan bersejarah tersebut agar mampu dipertahankan, diwariskan, dan dilanjutkan kepada generasi yang akan datang sehingga tetap bisa menjadi identitas dan karakter suatu kota. Metode yang digunakan pada paper ini yaitu metode studi literatur. Referensi literatur yang digunakan semuanya dikaitkan dengan urban, heritage dan tourism. Berdasarkan studi literatur yang telah dibuat, dapat disimpulkan bahwa urban heritage tourism merupakan sebuah konsep yang menggabungkan pariwisata dengan pemeliharaan bangunan bersejarah dengan cara memahami prinsip-prinsip heritage, merencanakan pelestarian untuk heritage, memahami prinsip-prinsip perencanaan dan pengembangan urban heritage tourism dan mengaplikasikan urban heritage tourism tanpa mengurangi nilai budaya yang berlaku sehingga urban heritage tourism memiliki peluang untuk menggambarkan masa lalu untuk disajikan pada masa kini dan yang selanjutnya sebagai daya tarik dari suatu kota.
\end{abstract}

Kata Kunci: heritage, konsep, tourism, urban

Info Artikel :

Diterima; 2021-10-21

Revisi; 2021-11-07

Disetujui; 2021-11-18 


\section{PENDAHULUAN}

Urban heritage merupakan layers/multilayering (lapisan-lapisan) yang terdiri dari sesuatu yang berharga yang berlokasi di area urban (perkotaan). Sesuatu yang dimaksud disini adalah sumber daya alam, kebudayaan, asli, sumber arkeologi, arsitektural, artistik, sosial dan teknologi yang diwariskan oleh generasi atau masyarakat di masa lampau, kepada generasi yang ada di masa sekarang dan dilanjutkan pewarisannya atau dilestarikan kepada generasi atau masyarakat yang akan datang karena memiliki nilai, kualitas, makna hubungan dan daya tarik. Pada umumnya kota-kota besar seperti di London, Paris, Amsterdam dan lain-lain bahkan kota-kota besar di Indonesia juga memiliki perjalanan sejarah ratusan tahun di abad 17-18 seperti di kota Jakarta, Semarang, Cirebon, Lasem, Surabaya dan lain-lain (Pawitro, 2015). Dari perjalanan sejarah yang sangat panjang tersebut menghasilkan tidak sedikit bangunan-bangunan bersejarah yang bernilai dan memiliki identitas tersendiri.

Pada gambar 1 menunjukkan bahwa penelitian-penelitian yang terkait dengan urban heritage menunjukkan peningkatan sejak tahun 2003 sampai saat ini. Topik pembahasan yang menarik lebih fokus mengenai kegiatan melestarikan dan mengelola bangunan bersejarah serta studi kasus terkait kota-kota yang dianggap memiliki sejarah yang cukup penting dalam sejarah dunia.

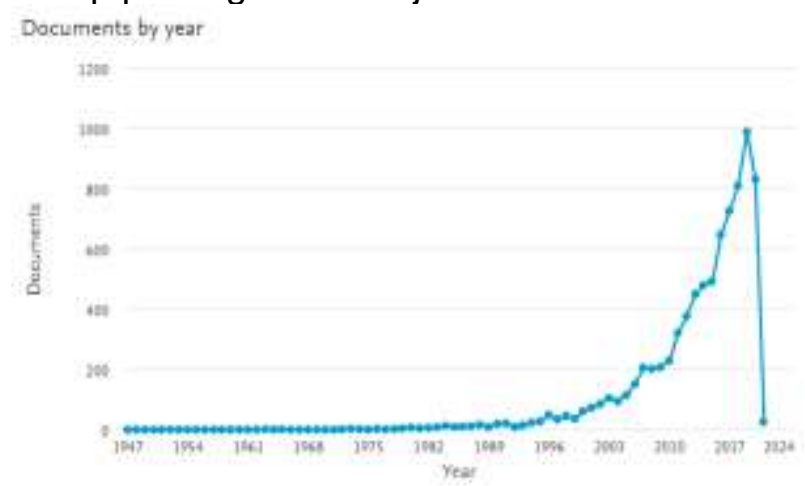

\section{Gambar 1 Dokumen Scopus tentang Penelitian Urban Heritage}

Masalah pelestarian bangunan bersejarah merupakan masalah yang sangat krusial karena dari suatu warisan ini apabila tetap dilestarikan nantinya akan menjadi identitas, menjadi karakter suatu kota yang dapat menguntungkan suatu kota sampai generasi yang akan datang. Heritage sendiri dianggap ideal atau normal ketika memenuhi prinsip-prinsip, norma-norma atau teori yang berlaku, namun kenyataannya yang terjadi saat ini adalah munculnya kecenderungan atau kejadian yang bertolak belakang dengan prinsip-prinsip tersebut. Heritage itu sendiri harus dilestarikan untuk generasi sekarang, namun yang terjadi saat ini adalah penghancuran dan peniadaan sehingga sangat penting kiranya sebuah kajian bagaimana cara melestarikan bangunan-bangunan bersejarah agar dapat tetap menjadi identitas dan karakter suatu kota? Penelitian ini bertujuan untuk mengetahui bagaimana cara melestarikan bangunan-bangunan bersejarah agar mampu menjadi identitas dan karakter suatu kota.

\section{METODE PENELITIAN}

Literatur review digunakan sebagai metode pembahasan dalam penelitian ini. Literature review merupakan salah satu metode yang menggunakan sumbersumber referensi untuk penelitian. Referensi tersebut dapat berbentuk buku, jurnal, artikel dan lain-lain. Dalam me-review literatur, makna yang diperoleh tidak sekedar hanya berupa bacaan saja namun bisa secara mendalam dalam mengevaluasi dan mengkritisi terkait penelitian-penelitian yang ada sebelumnya pada topik yang sama.

Literatur ilmiah seperti buku, laporan penelitian, disertasi, jurnal dan sumber internet merupakan referensi yang digunakan dalam paper ini. Referensi pada 
urban heritage tourism sendiri dimanfaatkan untuk mencari definisi, keterkaitan teori dan ruang lingkup pembahasan urban heritage tourism.

\section{HASIL DAN PEMBAHASAN \\ Urban}

Urban dalam Oxford Dictionary berarti terkait dengan kota. John Brickerhoff (1984) dalam (Taufikzk, 2013) menyatakan kota merupakan tempat tinggal manusia yang terdiri dari komponen seperti jalan, bangunan dan juga ruang terbuka hijau. Hal ini merupakan wujud dari perencanaan dan perancangan manusia. Sesuai dengan peraturan Mendagri RI No 4/1980, kota memiliki batasan-batasan administrasi yang jelas seperti kotamadya, kabupaten dan lain-lain dengan ciri non agraris dan memiliki fungsi sebagai pusat pertumbuhan. Dalam hal ini, peraturan mengenai batasan sebuah kota sangat jelas terlihat. Selanjutnya Amos Rapoport dalam Zikri (2013) mendefinisikan kota berdasarkan besaran dan ciri-cirinya. Definisi klasik kota adalah sebuah permukiman yang memiliki ukuran yang cukup besar, padat dan cenderung permanen. Sedangkan definisi modern kota adalah sebuah permukiman yang memiliki fungsi menghadirkan ruang-ruang yang efektif berdasarkan pengorganisasian ruang dan tatanan hirarki tersendiri. Sehingga masyarakat perkotaan dapat dilihat ciri-cirinya sebagai berikut ; (1) Heterogen; (2) Individualisme. (3) Dinamik; (4) Rasional (5) Birokrasi fungsional dan nilai-nilai secular; (6) Diversivikasi cultural; dan (7) Konsep pengandalan diri dan kelembagaan. Sehingga urban dapat diartikan sebagai suatu permukiman atau wadah yang terkait dengan kota, memiliki ukuran yang relative padat, permanen dan memiliki karakteristik suasana penghidupan yang modern bersifat non agraris (transformasi lingkungan alam ke lingkungan binaan), dihuni oleh orang-orang yang memiliki ciri-ciri heterogen, berorientasi pada rasionalitas, mobilitas sisial, mudah berbaur dan memiliki diversivikasi cultural, cenderung birokrasi fungsional, memiliki nilai-nilai secular dan individualis. Apabila dikaitkan dengan urban heritage, berdasarkan ciri-ciri yang disebutkan di awal maka permasalahan yang muncul di area urban itu lebih kompleks dibandingkan dengan rural. Oleh karena itulah mengapa permasalahan urban heritage di wilayah perkotaan lebih banyak diangkat dibandingkan dengan permasalahan di rural heritage.

\section{Heritage}

Heritage berarti warisan atau peninggalan. Arti kata heritage berdasarkan Collin Dictionary adalah sebagai; (1) sesuatu yang diwarisi saat lahir, pribadi, status, dan harta benda, (2) segala sesuatu yang telah diturunkan dari masa lalu atau diturunkan oleh tradisi, (3) bukti masa lalu, seperti situs sejarah, bangunan, dan lingkungan alam murni, yang secara kolektif dianggap sebagai warisan masyarakat saat ini, (4) sesuatu yang disediakan untuk orang atau kelompok tertentu atau hasil dari suatu tindakan, cara hidup, dan lain-lain (5) hukum properti apapun, terutama tanah, yang menurut hukum telah diturunkan atau mungkin diturunkan kepada ahli waris. Menurut Geddes \& Grosset (2003) dalam Indra (2009, p. 25) heritage dapat didefinisikan merupakan sesuatu yang mewarisi kelahiran, apapun yang berasal dari masa lalu atau tradisi situs bersejarah, dianggap sebagai warisan berharga dari masyarakat kontemporer. Selanjutnya definisi heritage oleh Whiteland, 1990 dalam Rahman (2012, p. 16) menyebutkan"Heritage has been regarde as accumulated experience, an educational encounter and a contact with previous generations". Menurut Whiteland, heritage telah dianggap sebagai pengalaman yang terakumulasi, pertemuan pendidikan, dan kontak dengan generasi sebelumnya. Berbeda dengan Whiteland, Nurick (2006) dalam Indra (2009, p. 25) mendefinisikan heritage adalah segala sesuatu yang diturunkan dari masa lalu, terutama: budaya asli dan materi alam; lingkungan binaan; sumber daya arkeologi; warisan tak benda; warisan alam, warisan itu dianggap oleh masyarakat multikultural kita memiliki kualitas atau signifikansi yang membuatnya layak untuk dilestarikan untuk kepentingannya sendiri dan untuk penghargaan terhadap generasi sekarang dan 
masa depan. Selanjutnya Pickard (2001, p. 5) mendefinisikan berdasarkan konvensi Granada heritage dibagi menurut tiga kelompok: (1) monumen (bangunan dan struktur), (2) kelompok bangunan, (3) situs yang memiliki kepentingan sejarah, arsitektur, arkeologi, seni, ilmiah, sosial atau teknologi yang mencolok. Selanjutnya Lim (1998) dalam Indra (2009, p. 27) berpendapat terkait dengan heritage"Heritage can be a counterpoise of the flux of such new values". Menurut Lim, heritage dapat menjadi penyeimbang arus nilai-nilai baru tersebut. Dapat disimpulkan bahwa heritage merupakan sesuatu yang berupa sumber daya alam, kebudayaan, asli, sumber arkeologi, arsitektural, artistik, sosial dan teknologi yang diwariskan oleh generasi atau masyarakat di masa lampau, kepada generasi yang ada di masa sekarang dan dlanjutkan pewarisannya atau dilestarikan kepada generasi atau masyarakat yang akan datang karena memiliki nilai, kualitas, makna hubungan dan daya tarik.

\section{Urban Heritage}

Untuk memahami urban heritage sebagai kesatuan frase, Karlstrom (2014) berpendapat bahwa urban heritage merupakan peninggalan fisik sejarah, yang merupakan daerah perkotaan kontemporer, yaitu peninggalan yang dibangun dengan nilai arsitektur dan sejarah atau "monumen" kota (gereja dan bangunan keagamaan lainnya, kastil, tembok kota, istana, dan bangunan kelembagaan. Umumnya, urban heritage didefinisikan sebagai lapisan). Sedangkan Hernadez et. al (2019) mendefinisikan urban heritage menjadi dua; (1) mengacu pada daftar elemen warisan yang terletak di daerah perkotaan; sisa-sisa arkeologi, bangunan bersejarah, arsitektur vernakular, taman sejarah, praktik sosial, ritual, dan acara perayaan (2) urban heritage dapat merujuk pada kota sebagai warisan, suatu jenis properti budaya khusus yang terutama terkait dengan lingkungan, pusat kota, dan kota bersejarah. Pendapat lain muncul terkait dengan definisi urban heritage yaitu Udeaja et al (2020) menekankan konsep urban heritage sebagai pelapisan nilai-nilai budaya dan alam serta atribut yang melampaui pengertian "pusat bersejarah" atau "ansambal" untuk mencakup konteks geografis perkotaan yang lebih luas.

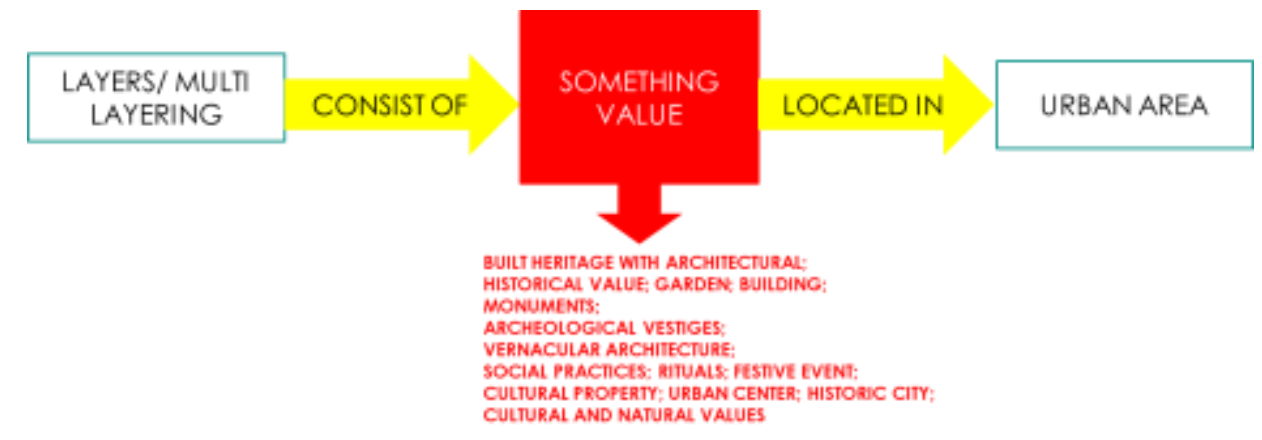

Gambar 2. Kerangka definisi Urban Heritage diolah dari Karlstrom (2004), Hernadez et. al (2019) dan Udeaja (2020)

Sehingga urban heritage dapat dimaknai sebagai layers/multilayering (lapisanlapisan) yang terdiri dari sesuatu yang berharga yang berlokasi di area urban (perkotaan).

Selanjutnya Ginting dan Wahid (2015) menyebutkan bahwa keberadaan bangunan cagar budaya atau bangunan bersejarah dan cerita pada masa lalu merupakan aspek terbesar yang membentuk jati diri. Ada empat faktor yang mempengaruhi identitas suatu tempat: kontinuitas, kekhasan, harga diri dan efikasi diri (TwiggerRoss and Uzzel, (1996). Urgensi dari peninggalan-peninggalan budaya masa lalu di kawasan perkotaan adalah bahwa aset tersebut mampu dijadikan sebagai identitas sebuah kota. Namun aset-aset urban heritage tersebut bisa jadi mengalami kemerosotan kualitas secara fisik apabila tidak segera melakukan upaya 
pelestarian. Di samping itu, perkembangan kota juga seringkali mengancam upayaupaya pelestarian terhadap benda-benda bersejarah.

\section{Prinsip-prinsip heritage}

Mengutip pernyataan yang diumumkan 12 November 1997 pada Deklarasi UNESCO tentang tanggungjawab generasi sekarang menuju generasi mendatang pasal 7 yang menyebutkan: "Dengan menghormati hak asasi manusia dan kebebasan fundamental, generasi sekarang harus menjaga keberagaman budaya umat manusia. Generasi sekarang memiliki tanggung jawab untuk mengidentifikasi, melindungi, dan menjaga warisan budaya yang berwujud dan tidak berwujud dan untuk mewariskan warisan bersama ini kepada generasi mendatang" (Bentley et al., 2009 , p. 410) Berdasarkan statement deklarasi UNESCO tersebut menegaskan bahwa heritage dikonotasikan memiliki nilai yang penting untuk dilestarikan oleh generasi sekarang dan dilanjutkan pelestariannya kepada generasi mendatang. Selanjutnya prinsip-prinsip pelestarian terhadap bangunan bersejarah termuat dalam Piagam Burra (Charter, 2003) :

1. Mempertahankan cultural significance dari 'place' dengan memperhatikan faktor pengamanan serta pemeliharaannya pada masa yang akan datang.

2. Kondisi awal fisik bangunan dijadikan dasar untuk melaksanakan konservasi.

3. Semua disiplin ilmu dilibatkan dalam penyelamatan 'place'.

4. Mempertimbangkan seluruh aspek-aspek 'signifikansi kultural' bukan sebagian.

5. Pelaksanaan konservasi diawali dengan penyelidikan secara cermat dan memberikan laporan akhir untuk prasyarat penetapan kebijakan konservasi.

6. Kegunaan yang paling tepat adalah yang dipilih oleh kebijakan konservasi.

7. Pemeliharaan terhadap 'visual setting' seperti skala, bentuk, warna, material dan tekstur.

8. Lokasi bersejarah hendaknya diletakkan di tempat semula, pemindahan keseluruhan atau sebagian tidak dapat diterima kecuali jika tidak ada cara lain.

9. Hal-hal yang tidak bisa diterima adalah bila bagian dari signifikansi cultural sebuah tempat berpindah isi pembentuknya.

\section{Planning for Heritage}

Agar aset-aset heritage tidak mengalami kemerosotan kualitas secara fisik, maka perlu upaya melakukan pelestarian. Menurut Direktorat Jenderal Pariwisata dan Universitas Gadjah Mada (1989) dalam Nuryanti (2009, p. 8) menyebutkan pendekatan perencanaan untuk heritage antara lain : (1) Conservation; suatu kegiatan atau upaya untuk melestarikan tatanan fisik atau aktivitas agar nilai atau makna tatanan dan aktivitas dapat dipertahankan. Nilai atau makna menggabungkan salah satu atau semua aspek berikut: budaya, sejarah, tradisional, seni, fungsional, lingkungan, dan pengalaman. Perspektif nilai atau makna ini terdiri dari apa yang ada di masa yang lalu, selanjutnya mencakup masa kini dan juga mewakili masa yang akan datang, (2) Gentrification; upaya untuk meningkatkan vitalitas pengaturan fisik dan aktivitas melalui perubahan struktural, (3) Rehabilitation; upaya untuk mengembalikan tatanan fisik dan aktivitas di suatu kawasan yang mengalami degradasi, (4) Renovation; upaya untuk mengubah tatanan fisik dan aktivitas untuk menyesuaikan atau mengakomodsi fungsi baru atau menyesuaikan tatanan lama dengan persyaratan baru melalui penggunaan ulang adaptif, (5) Restoration; upaya untuk memperbaiki kondisi fisik dan aktivitas dengan menghilangkan elemen baru atau tambahan dan mengganti elemen yang hilang untuk mengkonfirmasi dengan setting aslinya, dan (6) Reconstruction; upaya untuk mengembalikan keadaan fisik dan aktivitasnya sedekat mungkin dengan keadaan zaman sebelumnya. 
Ginting dan Wahid (2015) menyebutkan bahwa keberadaan bangunan cagar budaya atau bangunan bersejarah dan cerita pada masa lalu merupakan aspek terbesar yang membentuk jati diri. Ada empat faktor yang mempengaruhi identitas suatu tempat: kontinuitas, kekhasan, harga diri dan efikasi diri (Twigger-Ross \& Uzzel, 1996). Urgensi dari peninggalan-peninggalan budaya masa lalu di kawasan perkotaan adalah bahwa aset tersebut mampu dijadikan sebagai identitas sebuah kota. Namun aset-aset urban heritage tersebut bisa jadi mengalami kemerosotan kualitas secara fisik apabila tidak segera melakukan upaya pelestarian. Di samping itu, perkembangan kota juga seringkali mengancam upaya-upaya pelestarian terhadap benda-benda bersejarah.

Untuk mengatasi perkembangan kota yang sangat cepat, perlu kiranya memperhatikan upaya-upaya pelestarian salah satunya memahami prinsip-prinsip heritage itu sendiri. Prinsip pertama yaitu mempertahankan cultural significance dari 'place' dengan memerhatikan faktor-faktor pengamanan dan pemeliharaannya di masa yang akan datang. Kebudayaan setempat yang kuat akan terus memperkuat lokasi dari urban heritage itu sendiri sehingga mampu dipertahankan untuk generasi mendatang. Aspek-aspek signifikasi kultural tersubut harus dipertimbangkan secara menyeluruh bukan sebagian sehingga dapat membentuk totalitas. Selanjutnya kondisi awal fisik bangunan juga dijadikan dasar untuk melakukan konservasi. Bangunan dengan kondisi fisik awal yang sudah rapuh akan riskan dalam pemeliharaannya sehingga diperlukan penyelidikan yang sangat cermat sebagai dasar pertimbangan untuk kebijakan konservasi. Semua disiplin ilmu harus terlibat dalam penyelamatan 'place' tanpa terkecuali. Adapun untuk lokasi bersejarah hendaknya diletakkan di tempat semula, pemeliharaan tetap dilakukan terhadap 'visual setting' seperti skala, bentuk, warna, material dan tekstur. Adapun hal-hal yang tidak dapat diterima dalam prinsip-prinsip heritage sendiri adalah pemindahan keseluruhan atau sebagian kecuali jika tidak ada cara lain dan bila bagian dari signifikansi cultural sebuah tempat berpindah isi pembentuknya.

Upaya-upaya pelestarian juga dilakukan agar aset-aset heritage yang ada di area urban atau kota tidak mengalami kemerosotan kualitas secara fisik. Banyak hal yang dilakukan untuk menjaga aset-aset berharga tersebut antara lain dengan melakukan konservasi, gentrifikasi, rehabilitasi, renovasi, restorasi dan rekonstruksi. Tujuan dari melakukan upaya-upaya pelestarian ini tidak lepas dari mempertahankan dan memperkuat identitas dimana heritage tersebut berasal.

\section{Tourism}

Salah satu penggerak ekonomi terutama bagi negara-negara berkembang adalah melalui pariwisata (Kundu et al., 2012). Organisasi Pariwisata Dunia (WTO) dalam (Pitana \& Diarta, 2009) mengartikan tourism sebagai aktivitas perjalanan yang dilakukan manusia di luar lingkungan sehari-harinya. Menurut Meyers (2009) pariwisata merupakan kunjungan yang dilakukan di luar lokasi kediaman normal wisatawan (visitor) selama lebih dari 24 jam. Selanjutnya Herman V. Sculard dalam Yoeti (1996, p. 114) menyatakan kegiatan pariwisata terkait dengan perekonomian dimana adanya orang-orang asing masuk kedalam suatu negara, kota atau daerah tertentu.

Salah satu tujuan dari pariwisata adalah untuk meningkatkan kualitas hidup wisatawan melalui berberapa cara antara lain seperti bersantai, istirahat, rekreasi dan menambah ilmu dan wawasan yang baru (Constanta, 2009). Meyers (2009) menyebutkan tujuan yang lain yaitu untuk memenuhi rasa keingintahuan suatu lokasi, liburan atau menghabiskan waktu luang serta tujuan lainnya.

Untuk menunjang keberhasilan pariwisata, berdasarkan Cooper dkk dalam Sunaryo (2013, p. 159) ada lima aspek yang harus diperhatikan dalam pengembangan tujuan pariwisata yaitu :

1. Attraction atau daya tarik wisata

2. Accesibility atau aksesibilitas

3. Amenities atau amenitas 
4. Ancillary Service atau fasilitas umum

5. Institution atau kelembagaan

\section{Tourism sebagai salah satu upaya dalam pelestarian}

Selain mengupayakan pelestarian dengan melakukan konservasi, gentrifikasi, rehabilitasi, renovasi dan rekonstruksi, pariwisata juga dipilih untuk menjadi bagian dari upaya pelestarian. Sesuai dengan tujuan dari pariwisata yaitu salah satunya untuk menambah ilmu dan wawasan baru, dan memenuhi rasa keingintahuan suatu lokasi maka pengelolaan urban heritage melalui kegiatan wisata ini menjadi pilihan bagi pengunjung dengan minat khusus untuk dapat lebih dekat mengenal warisan bersejarah dengan lebih menyenangkan. Dalam pariwisata sendiri ada attraction atau daya tarik wisata yang menjadi modal kepariwisataan yang dapat menarik pengunjung untuk mendatangi tempat-tempat bersejarah ini. Selain attraction, ada aksesibilitas, amenitas dan fasilitas umum serta kelembagaan untuk melengkapi keberhasilan pariwisata.

Dalam dunia pariwisata terdapat konsep-konsep pariwisata yang dikembangkan di seluruh dunia. Ada enam konsep yaitu: (1) urban ecotourism, (2) creative city, (3) fantasy city, (4) resort city, (5) cultural city, (6) tourist-historic city (Adriani, 2011). Salah satu konsep yang mengangkat urban heritage adalah konsep tourist-historic city. Konsep ini menjadikan heritage sebagai daya tarik untuk dikunjungi. Morfologi perkotaan serta lingkungan yang memiliki nilai sejarah arsitektur, keberhasilan artistik, dan event sejarah serta akumulasi artefak budayanya merupakan komponen-komponen dari kota wisata bersejarah (Asworth \& Tunbridge, 1990, p. 72). Selanjutnya Asworth dan Tunbridge (1990, p. 57) menyampaikan bahwa mulai abad 16 kota wisata bersejarah sudah mulai berkembang dan konsep ini berkembang selaras dengan kemajuan pariwisata perkotaan. Menurut Asworth dan Tunbridge (1990;72) langkah-langkah konservasi harus diperhatikan dalam konsep pariwisata perkotaan sehingga peninggalan sejarah tetap terjaga sebagai daya tarik yang menarik bagi wisatawan.

\section{Keterkaitan urban heritage dengan tourism}

Kota adalah bagian dari tujuan pariwisata yang fundamental di dunia mulai tahun 1980-an (Law, 1996, p. 1), karena kota memiliki heterogenitas yang berhubungan dengan budaya, lifestyle, dan ajakan yang berbeda terhadap perjalanan dan liburan (S. Page, 1995, p. 1). Arti kota bagi pariwisata adalah sangat penting. Page (1995, p. 9) menyebutkan sebuah kota akan menarik dilihat karakternya dilihat: (1) sifatnya yang heterogen, (2) memiliki fungsi-fungsi yang berbeda atau multifungsi seperti pusat perdagangan, pusat pemerintahan dan destinasi pariwisata, (3) fungsi-fungsi yang berkembang tersebut dimanfaatkan sebagai konsumsi para pengunjung dan macam-macam pengguna. Sedangkan arti pariwisata bagi kota menurut Page (2003) yaitu: (1) memperkuat perekonomian, (2) mendorong penyediaan transportasi daerah dan pembangunan perkotaan, (3) melalui pariwisata perekonomian lokal dapat direvitalisasi.

Dalam menentukan bagian pasar yang mana dari jenis pengunjung atau wisatawan yang akan diperoleh serta kegiatan wisata sejarah apa saja yang akan dilakukan maka harus menyesuaikan dengan sifat dan karakter peninggalan sejarah yang ada di tempat tersebut. Antara urban heritage dan tourism terdapat keterkaitan yaitu dimana pariwisata (tourism) digunakan sebagai alat untuk mempertahakan atau melestarikan peninggalan-peninggalan bersejarah (urban heritage) dengan memenuhi prinsip-prinsip, persyaratan dan planning untuk heritage.

Upaya mempertahankan urban heritage melalui tourism diaplikasikan pada urban heritage tourism. Urban heritage tourism sendiri dapat dimaknai sebagai suatu kegiatan wisata untuk melihat sesuatu yang berupa sumber daya alam, kebudayaan asli, sumber arkeologi, arsitektural, artistik, sosial dan teknologi yang berlokasi di daerah urban atau perkotaan. Dalam hal ini urgensi yang muncul pada pemaknaan tersebut adalah perlunya melestarikan bangunan-bangunan dan budaya yang 
bersejarah dari kepunahan, salah satu ativitas dalam pewarisan urban heritage tersebut adalah melalui aktivitas pariwisata dan pengelolaan urban heritage itu sendiri. Sehingga diharapkan urban heritage tersebut mampu dipertahankan, diwariskan, dan dilanjutkan kepada generasi yang akan datang melalui kegiatan wisata dan bisa menjadi identitas dan karakter suatu kota. Widyastuti (2011) menegaskan dalam urban heritage tourism terdapat pembatasan yang tegas terhadap hal-hal yang bertentangan dengan penurunan nilai-nilai budaya yang luhur harus dilarang.

\section{Prinsip-prinsip perencanaan dalam mengembangkan urban heritage tourism}

Menurut Widiastuty (2011), prinsip-prinsip perencanaan dalam mengembangkan urban heritage tourism adalah :

1. Mengusahakan lokasi penginapan dekat dengan lokasi atraksi.

2. Menyediakan pemasaran akomodasi penginapan.

3. Menyediakan area pejalan kaki bagi pengunjung.

4. Menggunakan alat yang dapat mengatur tampilan bangunan-bangunan kuno bersejarah dan ruang terbuka.

5. Apabila memungkinkan, menggunakan kawasan bersejarah seperlunya.

6. Menampilkan tatanan atraksi untuk para pengunjung.

7. Mencegah penurunan kualitas lingkungan.

8. Menyediakan infrastruktur.

9. Melakukan pembongkaran terhadap fasilitas wisata jika hal tersebut mengganggu kegiatan wisata.

\section{KESIMPULAN DAN SARAN}

Dari pembahasan yang telah disampaikan sebelumnya dapat disimpulkan bahwa cara melestarikan bangunan-bangunan bersejarah agar tetap menjadi identitas dan karakter suatu kota dapat dilakukan dengan pendekatan pariwisata dengan cara: (1) memahami prinsip-prinsip heritage, (2) merencanakan pelestarian untuk heritage, (3) memahami prinsip-prinsip perencanaan dan pengembangan urban heritage tourism, dan (4) mengaplikasikan urban heritage tourism tanpa mengurangi nilainilai budaya yang berlaku.

\section{UCAPAN TERIMA KASIH}

Trimakasih kepada Pak Ikaputra atas bimbingan dan arahan dalam penulisan artikel literatur review ini.

\section{DAFTAR PUSTAKA}

Adriani, $\quad$ Y. (2011). Pariwisata Perkotaan. http://tentangpariwisata.blogspot.com/2011/01/pariwisata-perkotaan-teori-dankonsep.html diakses tanggal 10 Desember 2020

Al, U. et. (2020). Urban Heritage Conservation and Rapid Urbanization: Insights from Surat, India. Sustainability Journal, 12(6).

Asworth, G. J., \& Tunbridge, J. E. (1990). The Tourist-Historic City. John Wiley \& Sons.

Bentley, R. A., Maschner, H. D. G., \& Chippindale, C. (Eds.). (2009). Handbook of Archaeological Theories. Altamira Press.

Charter, B. (2003). Pedoman dan Prinsip-prinsip Preservasi dan Konservasi Bangunan dan Lingkungan Bersejarah-Burra Charter. World Heritage Council UNESCO Publisher.

Constanta, E. (2009). The Impact of tourism in enchancing the quality of life. Review of International Comparative Management, 10(2), 347-351.

Ginting, \& Wahid. (2015). Exploring Identity's Aspect of Continuity of Urban Heritage Tourism. Procedia-Social And Behavioral Sciences, 234-241.

Indra, M. I. (2009). Pengembangam Pasar Baru. Universitas Indonesia.

Karlstrom A. (2014). Urban Heritage. In: Smith C. (eds) Encyclopedia of Global 
Archaelogy (I. S. S C (Ed.); Encycloped). Springer. https://doi.org/https://doi.org/10.1007/978-1-4419-0465-2_1137

Kundu, Suman, \& Kumas. (2012). Economic empowerment through rural tourism: the case of Tarapith-a-religgious tourism destination in Birbhum District of West Bengal India. Geografia. Malaysia Journal of Society and Place, 8(7).

Law, C. M. (1996). Tourism in Major City. International Thomson Business Press.

Meyers, K. (2009). Panduan Pelaksanaan Ekowisata. Unesco.

Nuryanti, W. (2009). The Role of Heritage Tourism in Community Planning and Development (W. Nuryanti (Ed.)).

Page, S. (1995). Urban Tourism. Routledge.

Page, S. J., Hall, \& Michael, C. (2003). Managing Urban Tourism. Pearson Education Limited.

Pawitro, U. (2015). Preservasi-Konservasi Bangunan Bersejarah dan Pengelolaan Kawasan Kota Lama. Simposium Nasional RAPI XIV.

Pickard, R. (2001). Policy and Law in Heritage Conservation. Spon Press.

Pitana, I. G., \& Diarta, I. K. S. (2009). Pengantar IImu Pariwisata. Andi.

Rahman, S. (2012). Heritage Tourism and the Built Environment [disertasi]. University of Birmingham UK.

Sunaryo, B. (2013). Kebijakan Pembangunan Destinasi Pariwisata Konsep dan Aplikasinya di Indonesia. Gava Media.

Taufikzk. (2013). Pengertian Kota Menurut Para Ahli. http://taufikzk.wordpress.com/2013/11/28/pengertian-kota-menurut-para -ahli/ diakses 1 November 2020

Twigger-Ross, C. L., \& Uzzel, D. L. (1996). Place and identity process. Journal of Environmental Psycology, 16, 205-220.

Widyastuti, A. A. S. A. (2011). Urban Heritage Tourism Kawasan Jalan Thamrin Denpasar Bali. Jurnal Teknik WAKTU, 9(1).

Yoeti, O. A. (1996). Pengantar Ilmu Pariwisata. Angkasa.

Zikri, A. (2013). Definisi Kota dan desa. http://ahluldesigners.blogspot.com/2012/05/normal-0-false-false-in-x-nonex.html diakses 1 November 2020 